\title{
Blaasruptuur na 'minor' trauma en alcoholgebruik
}

\author{
Madeline D. C. Vergunst ${ }^{1}$ - Rob J. A. M. Davits ${ }^{1}$
}

Published online: 4 September 2017

(C) The Author(s) 2017. This article is an open access publication.

Samenvatting Een 33-jarige man bezocht de Spoedeisende Hulp (SEH) in verband met klachten van acute buikpijn na een val op zijn buik en aangezicht na alcoholgebruik. Bij aanvullend onderzoek werd vrij vocht gezien in de buik en contrastlekkage vanuit de blaas. De patiënt werd opgenomen wegens een geïsoleerde traumatische blaasruptuur en conservatief behandeld met een verblijfskatheter gedurende zeven dagen en een tiendaagse antibioticakuur. Een geïsoleerde blaasruptuur is zeldzaam en kan levensbedreigend zijn indien de diagnose gemist wordt. Alcoholintoxicatie is een risicofactor voor het ontstaan van een blaasdistensie en -ruptuur.

Trefwoorden alcoholintoxicatie - stomp buiktrauma . geïsoleerde blaasruptuur

\section{Bladder rupture after 'minor' trauma and alcohol ingestion}

Abstract A 33-year-old man visited the emergency department with complaints of acute abdominal pain after a blunt abdominal trauma and alcohol intoxication. Diagnostic investigations revealed free abdominal fluids and contrast leakage from the bladder. Patient was admitted to the hospital for conservative treatment of an isolated traumatic bladder rupture, consisting of an indwelling bladder catheter for seven days and an antibiotic treatment for 10 days. An isolated bladder rupture is rare and can be life threatening if

Madeline D. C. Verguns

madelinevergunst@gmail.com

1 afdeling Urologie, TweeSteden Ziekenhuis, Tilburg, Nederland the diagnosis is missed. Alcohol intoxication is a risk factor for a bladder distention and rupture.

Keywords isolated bladder rupture - minor trauma . alcohol intoxication

\section{Inleiding}

Blaasrupturen zijn in meer dan $90 \%$ van de gevallen gerelateerd aan een bekkenfractuur. Een geïsoleerde blaasruptuur is zeldzaam en wordt, door de atypische symptomen ervan, in eerste instantie vaak niet onderkend, waardoor het beloop levensbedreigend kan zijn. In de literatuur zijn geïsoleerde blaasrupturen beschreven na alcoholgebruik in combinatie met een 'minor' trauma [1-4]. In dit artikel beschrijven wij een aan alcohol gerelateerde casus.

\section{Casus}

Een 33-jarige man met een blanco voorgeschiedenis bezocht de Spoedeisende Eerste Hulp (SEH) in verband met toenemende pijn in de onderbuik. De klachten waren ontstaan nadat hij de avond daarvoor na het drinken van meer dan 20 eenheden alcohol voorover op zijn aangezicht en buik op een houten vloer was gevallen. Bij de huisarts werd in de morgen voorafgaand aan het SEH-bezoek een urineretentie vastgesteld.

Bij lichamelijk onderzoek werd een transpirerende zieke patiënt gezien, met tachycardie (hartfrequentie 140/min), een ademhalingsfrequentie van $36 / \mathrm{min}$, een temperatuur van $38,6^{\circ} \mathrm{C}$ en een bolle buik. Over het abdomen werd zeer spaarzame peristaltiek gehoord, de buik was diffuus drukpijnlijk en geprikkeld. 


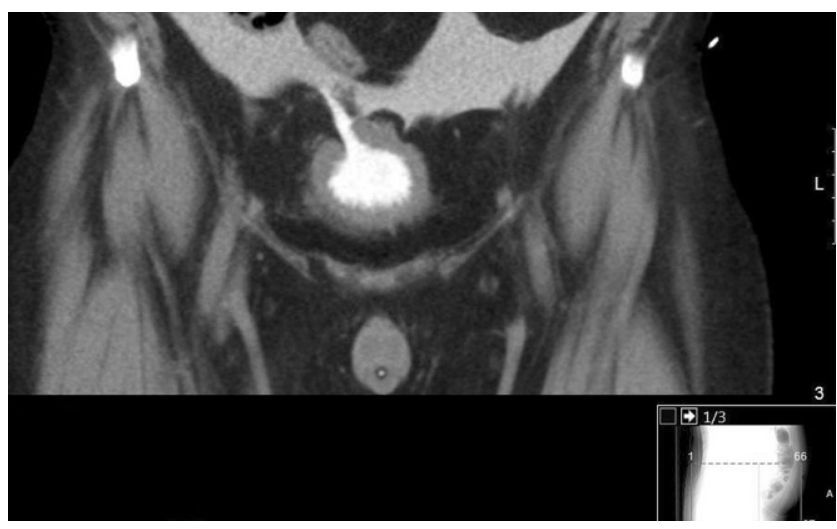

Figuur 1 Coronaal beeld van de CT-scan met mictiecystografie.

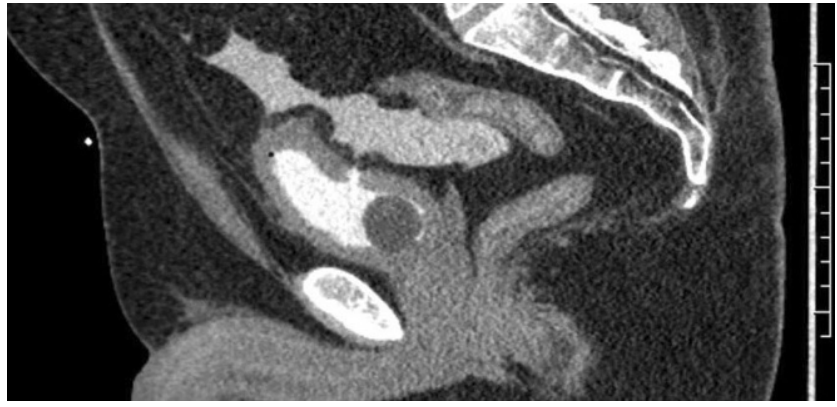

Figuur 2 Sagittaal beeld van de CT-scan met mictiecystografie.

Met de bladderscan werd een urineretentie van $400 \mathrm{cc}$ vastgesteld. Na het inbrengen van een catheter à demeure (CAD) liep circa $150 \mathrm{cc}$ heldere urine af. Laboratoriumonderzoek toonde $\mathrm{Hb} 9,8 \mathrm{mmol} / \mathrm{l}$, leukocytenaantal $16,1 \times$ $10^{9} / \mathrm{l}$, creatinine $233 \mu \mathrm{mol} / \mathrm{l}$, CRP 13 , natrium $128 \mathrm{mmol} / \mathrm{l}$, lactaat 6,9, ALAT 116, LDH 439 en GGT 109. Het urinesediment toonde veel erytrocyten en leukocyten.

Echografisch werd er vrij vocht in de buik gezien, wat werd bevestigd middels een CT-abdomen met intraveneus contrast, waarbij het vrije vocht verspreid bleek te zijn rond de lever en de milt, in beide flanken, alsmede in het kleine bekken. De blaaskatheter was in situ. Aan de craniale dorsale zijde van blaas werd een focale onregelmatigheid gezien en er waren enkele kleine luchtbellen zichtbaar in de blaas. Er was sprake van lekkage van contrast naar de buikholte vanuit een craniaal gelegen letsel aan de achterzijde van de blaas (fig. 1 en fig. 2). Er was geen aanwijzing voor een intra-abdominale bloeding. Evenmin waren er tekenen van ander orgaan- of botletsel.

Er volgde opname, waarbij werd gestart met een conservatief beleid bestaande uit een CAD en een tiendaagse orale antibioticakuur. De volgende dag werd de patiënt in goede toestand ontslagen. Na een week werd een X-mictiecystogram gemaakt, waarbij geen sprake meer was van contrastlekkage vanuit de blaas. Hierop werd de CAD klinisch verwijderd.
Daags na het verwijderen van de CAD kwam de patiënt opnieuw op de SEH, met opnieuw een urineretentie, deze keer van $1,5 \mathrm{~L}$, die wederom was ontstaan na het drinken van een grote hoeveelheid alcohol. Hij kreeg opnieuw een CAD gedurende drie dagen en bovendien werd gestart met tamsulosine. Na zes weken werd een cystoscopie uitgevoerd. Hierop was craniaal in de blaas een goed genezen litteken te zien van ca. $4 \mathrm{~cm}$ lengte. Verder werden er op de CAD geen afwijkingen waargenomen. Patiënt gaf aan geen klachten meer gehad te hebben en er werd een followupafspraak gemaakt voor over een jaar.

\section{Bespreking}

De blaas is een orgaan dat zelden beschadigd raakt, mede dankzij de relatief beschermde anatomische locatie diep in het bekken.

Aan een blaasruptuur kunnen verschillende mechanismen ten grondslag liggen. Meestal is er sprake van een traumatische blaasruptuur, die in meer dan $90 \%$ van de gevallen veroorzaakt wordt door directe perforatie van de blaaswand als gevolg van een bekkenfractuur of, indirect, door tractie van omgevende ligamenten. Een geïsoleerde blaasruptuur die het gevolg is van een geforceerde compressie van een volle blaas, zonder geassocieerde bekkenfractuur, komt minder vaak voor. Een stomp trauma of een val kan een intravesicale shockwave genereren, die een ruptuur kan veroorzaken door de plotselinge rek in het posteriosuperieure deel van de blaas, de meest mobiele en tevens zwakste plek van de blaas [1-3]. Een geïsoleerde blaasruptuur is meestal intraperitoneaal, in tegenstelling tot een traumatische blaasruptuur, die meestal extraperitoneaal is. Andere oorzaken van een geïsoleerde blaasruptuur hangen samen met intrinsieke risicofactoren, zoals blaasstenen, acute of chronische infectie, radiotherapie, een neurogene blaas, acute obstructie van de urethra of blaashals, of een maligniteit in de blaas of het kleine bekken [3-5]. Ook patiënten bij wie op jonge leeftijd een blaasaugmentatie is uitgevoerd, blijken een verhoogd risico op een (spontane) geïsoleerde blaasruptuur te hebben, met een incidentie van ca. 8,6-13\%. Veel van deze patiënten hebben een gestoorde vullingssensatie, waardoor er ongemerkt overrekking van de blaas kan ontstaan, met het risico op perforatie. Derhalve dient men bij deze patiëntenpopulatie extra alert te zijn op een blaasperforatie bij buikpijn en onverklaarde koorts.

Alcoholintoxicatie wordt in toenemende mate als oorzaak beschreven van een geïsoleerde blaasruptuur bij een gezonde blaas, zonder intrinsieke risicofactoren. Enerzijds wordt het risico op een blaasruptuur bij alcoholintoxicatie vergroot doordat intoxicatie leidt tot een verminderde vullingssensatie van de blaas. Anderzijds verhoogt het grote volume alcohol en het diuretische effect ervan de vulling 
van de blaas, vaak tot een punt van overrekking. Deze overrekking kan leiden tot atonie van de blaas, die uiteindelijk zo uitgerekt en dun is geworden dat zelfs een klein trauma tot een ruptuur kan leiden. Tevens zorgen misselijkheid en braken bij intoxicatie voor een verhoogde intraabdominale druk. Kleine traumata worden door de (alcohol)geïntoxiceerde patiënt vaak vergeten, waardoor de verdenking op een traumatisch blaasruptuur nog al eens over het hoofd gezien wordt [2, 3].

Symptomen van een intraperitoneale blaasruptuur zijn meestal aspecifiek, wat kan leiden tot vertraging bij het stellen van de juiste diagnose. Klinische signalen kunnen zijn: een anamnese van een trauma van de onderbuik, peritoneale prikkeling, macroscopische hematurie, suprapubische pijn, oligurie of anurie, of een opgezette buik door intraabdominale vochtophoping. Bij een niet tijdig gestelde diagnose kunnen patiënten zich presenteren met tekenen van een peritonitis of sepsis, wat tot levensbedreigende situaties kan leiden [1, 3, 4]. Peritoneale absorptie van creatinine en ureum kan een vertekend beeld van het laboratoriumonderzoek geven en zich presenteren als acuut nierfalen.

De diagnose kan het beste worden bevestigd door middel van een conventionele retrograde cystografie of CT-cystografie, die een equivalente detectiewaarde hebben, met een sensitiviteit en specificiteit van $95 \%$ en $100 \%$ respectievelijk $[6,7]$. Echografie kan gebruikt worden om te zien of er sprake is van vrij vocht in de buik, maar heeft verder geen specifieke diagnostische waarde. Paracentese kan een intraperitoneale blaasruptuur verder bevestigen door verhoogde kreatininespiegels in ascites aan te tonen.

Extraperitoneale blaasrupturen worden doorgaans conservatief behandeld door middel van katheterdrainage, gevolgd door een cystogram na 10 dagen. Het merendeel van de extraperitoneale rupturen is binnen twee tot drie weken genezen. Voor intraperitoneale blaasrupturen is over het algemeen primair chirurgische behandeling aangewezen, vanwege de vrees voor contaminatie van de intraperitoneale holte $[2,7,8]$, maar voor kleine intraperitoneale blaasperforaties is, onder bepaalde omstandigheden, ook conservatieve behandeling een optie [9-11]. Omdat bij onze patiënt ook sprake leek te zijn van een kleine ruptuur, werd volstaan met een conservatief beleid. Op grond van de bevindingen bij controlecystoscopie kan echter worden aangenomen dat de perforatie groter is geweest dan aanvankelijk werd verondersteld. Desondanks bleek een conservatieve behandeling succesvol.

\section{Conclusie}

Een geïsoleerde blaasruptuur moet overwogen worden bij patiënten die zich presenteren met abdominale pijn, hema- turie en mictieklachten. Alcoholintoxicatie lijkt een risicofactor te zijn voor een geïsoleerde blaasruptuur. Het initieel missen van de diagnose kan leiden tot een hoge morbiditeit en mortaliteit, doordat zich een peritonitis en sepsis kan ontwikkelen. Het beste beeldvormende onderzoek voor het bevestigen van de diagnose is retrograde cystografie. Behandeling kan bestaan uit enkel urinedrainage door middel van een $\mathrm{CAD}$, maar bij grote intraperitoneale blaasrupturen is chirurgische sluiting van het blaasdefect noodzakelijk.

Open Access This article is distributed under the terms of the Creative Commons Attribution 4.0 International License (http:// creativecommons.org/licenses/by/4.0/), which permits unrestricted use, distribution, and reproduction in any medium, provided you give appropriate credit to the original author(s) and the source, provide a link to the Creative Commons license, and indicate if changes were made.

\section{Literatuur}

1. Sezhian N, Rimal D, Suresh G. Isolated intraperitoneal bladder rupture following minor trauma after alcohol ingestion. South Med J. 2005;98(5):573-4.

2. Mellema CT, Henneman O, Leenarts JA, Puylaert JB. Spontaneous rupture of the bladder. Ned Tijdschr Geneeskd. 2004;148(15): 735-40.

3. Herd AM, Crofts NG, Lee LM, Girard JV, Sweetland RJ. Isolated bladder rupture after minor trauma in a patient with alcohol intoxication. J Emerg Med. 1994;12(3):409-11.

4. Kivlin D, Ross C, Lester K, Metro M, Ginsberg P. A case series of spontaneous rupture of the urinary bladder. Curr Urol. 2015;8(1):53-6.

5. Parker H, Hoonpongsimanont W, Vaca F, Lotfipour S. Spontaneous bladder rupture in association with alcoholic binge: a case report and review of the literature. J Emerg Med. 2009;37(4):386-9.

6. Iverson AJ, Morey AF. Radiographic evaluation of suspected bladder rupture following blunt trauma: critical review. World J Surg. 2001;25(12):1588-91.

7. Zonca P, Cambal M, Jacobi CA. Laparoscopic management of spontaneous intraperitoneal perforation of urinary bladder. Bratisl Lek Listy. 2011;112(5):282-6.

8. Maheshwari PN, Bhandarkar DS, Shah RS. Laparoscopic repair of idiopathic perforation of urinary bladder. Surg Laparosc Endosc Percutan Tech. 2005;15(4):246-8.

9. Moreno-Alarcon C, Rigabert-Montiel M, Lopez-Cubillana P, Gomez-Gomez G. Conservative management is a reasonable option in intraperitoneal bladder rupture. Arch Esp Urol. 2014;67(9): 788-91.

10. Mahfouz AI, Sayer T, Phillips C. Conservative management of spontaneous rupture of the urinary bladder. Int Urogynecol $\mathrm{J}$. 2011;22(5):629-31.

11. Craggs B, Michielsen D. Conservative treatment of an intraperitoneal bladder perforation. Cent European J Urol. 2011;64(1):47-9.

Madeline D.C. Vergunst basisarts/anios

drs. Rob J.A.M. Davits uroloog 